\title{
Tumour Emboli Causing Multifocal Ischemic Stroke from Intracardiac Malignant Solitary Fibrous Tumour
}

Lindsay Melvin MD, Nicole Sitzer MD, Rebecca Amer MD

\author{
About the Authors: \\ Lindsay Melvin is an Assistant Professor in the Department of Medicine at the University of Toronto. Nicole Sitzer is a Respirologist \\ with a community practice. Rebecca Amer is an Associate Professor, Divisions of General Internal Medicine and Respirology, \\ Department of Medicine \\ Correspondence to Lindsay Melvin: lindsay.melvin@uhn.ca \\ Submitted: January 5, 2018. Accepted: April 8, 2018. Published: November 9, 2018. DOI: 10.22374/cjgim.v13i4.268
}

\begin{abstract}
A 78-year-old woman presented to the emergency department with gait ataxia and diplopia. Her past medical history included the surgical resection of a phyllodes breast tumour 8 years prior, with no known recurrence. A computed tomography (CT) scan of the brain demonstrated multifocal right supratentorial hemispheric subacute infarcts in the frontoparietal, posterior temporal and occipital regions. The patient developed recurrent generalized seizures in hospital. Transesophageal echocardiogram demonstrated a large $2.7 \times 1.8 \times 0.8 \mathrm{~cm}$ mobile echogenic mass attached to the left posterior atrial wall. CT angiogram of the chest revealed the left atrial mass as well as a mass encasing the right bronchus intermedius. The patient opted for comfort care and passed away in hospital. Autopsy revealed the tumour to be a primary cardiac solitary fibrous tumour. We present a case of multifocal ischemic stroke and seizures secondary to tumour emboli originating from intracardiac solitary fibrous tumour.
\end{abstract}

\section{RESUME}

Une femme de 78 ans s'est présentée au service des urgences avec une ataxie et une diplopie de la démarche. Ses antécédents médicaux comprenaient la résection chirurgicale d'une tumeur à phyllodes au sein 8 ans auparavant, sans récidive connue. Une tomodensitométrie (TDM) du cerveau a révélé des infarctus subaigus hémisphériques suprasensoriels droits dans les régions frontopariétale, postérieure temporale et occipitale. Le patient a développé des crises généralisées récurrentes à l'hôpital.

Léchocardiogramme transœsophagien a mis en évidence une masse échogène mobile importante de $2,7 \times 1,8 \times 0,8 \mathrm{~cm}$ fixée à la paroi auriculaire postérieure gauche. La tomodensitométrie thoracique révélait la masse auriculaire gauche ainsi qu'une masse recouvrant la bronche intermédiaire. Le patient a opté pour des soins de confort et est décédé à l'hôpital. Lautopsie a révélé que la tumeur était une tumeur fibreuse solitaire cardiaque primaire. Nous présentons un cas d'accident vasculaire cérébral ischémique multifocal et de convulsions secondaires à une embolie tumorale provenant d'une tumeur fibreuse solitaire intracardiaque. 


\section{Case}

A 78-year-old woman presented to the emergency department with a 3-week history of ataxia and diplopia. Her past medical history was significant for surgical resection of a phyllodes breast tumour with no known recurrence of disease. Physical examination revealed a left cranial nerve III palsy, ataxia and left-sided weakness. A non-contrast computed tomography (CT) head demonstrated multifocal subacute infarcts in the frontoparietal, posterior temporal and occipital regions. A transthoracic echocardiogram showed no evidence of an intracardiac mass.

The patient developed recurrent generalized seizures during her hospitalization. Magnetic resonance imaging of the head confirmed multifocal acute ischemic infarcts suggestive of a cardio-embolic source. CT of the chest demonstrated a 3.3 $\mathrm{cm}$ bi-lobed atrial mass on the posterior wall of the left atrium, extending into the right inferior pulmonary vein and encasing the right bronchus intermedius (Figure 1). Several nodules in the peripheral branches of the pulmonary vein were also present. A transesophageal echocardiogram confirmed the presence of a large $2.7 \times 1.8 \times 0.8 \mathrm{~cm}$ mobile echogenic mass attached to the posterior left atrial wall which was not seen on the transthoracic imaging (Figure 2).

The patient opted for non-acute management of her disease and died two months later. A limited autopsy revealed a $5 \times 4$ $\times 3 \mathrm{~cm}$ malignant solitary fibrous tumour in the left atrium invading the left ventricle, interventricular septum and epicardial fat (Figure 3). The tumour also extended into the pulmonary vein and infiltrated the vessel wall. Multiple branches of the pulmonary vein were filled with emboli-like tumour nodules. The tumour demonstrated areas of hypercellularity, necrosis, and high mitotic activity, consistent with a high-grade malignancy.
Despite initial clinical suspicion of recurrence of her phyllodes breast tumour with metastases, the final pathology was indicative of a malignant solitary fibrous tumour.

\section{Discussion}

Approximately $20 \%$ of ischemic strokes are thought to be cardioembolic in nature. ${ }^{1}$ Features on clinical presentation suggestive of cardioembolism include: decreased level of consciousness, maximum severity of symptoms at onset with quick recovery of deficits, symptoms involving multiple vascular territories of the brain and the presence of non-central nervous system emboli. Cardiac sources of cerebral emboli include valvular disease, left atrial or ventricular thrombi, and cardiac tumours. Paradoxical emboli may occur when there is reversal of flow through a patent foramen ovale, atrial or ventricular septal defect. ${ }^{1}$

Primary cardiac tumours are uncommon with rates reported between $0.001-0.28 \% .^{2-4}$ Over $75 \%$ of primary cardiac tumours are benign. Secondary cardiac tumours are more common; $2.3-18.3 \%$ of patients with a primary neoplasm have cardiac metastases on post-mortem examination. Secondary cardiac tumours may arise from extension of a primary tumour or are metastastic lesions from extracardiac malignancies. ${ }^{3,5}$ Malignancies which most commonly metastasize to the heart and pericardium include mesothelioma, lung adenocarcinoma, melanoma, breast carcinoma and lymphoproliferative neoplasms. ${ }^{3,6,7}$ Clinical manifestations of cardiac tumours vary depending on tumour location. Patients may present with chest pain, heart failure, pericardial effusion, or arrhythmia. Cardioembolic stroke as a presenting feature of a cardiac tumour is an extremely rare occurrence. ${ }^{3,6}$

Solitary fibrous tumours (SFTs) are neoplasms of spindle cells, which originate from mesenchymal cells. SFTs are usually

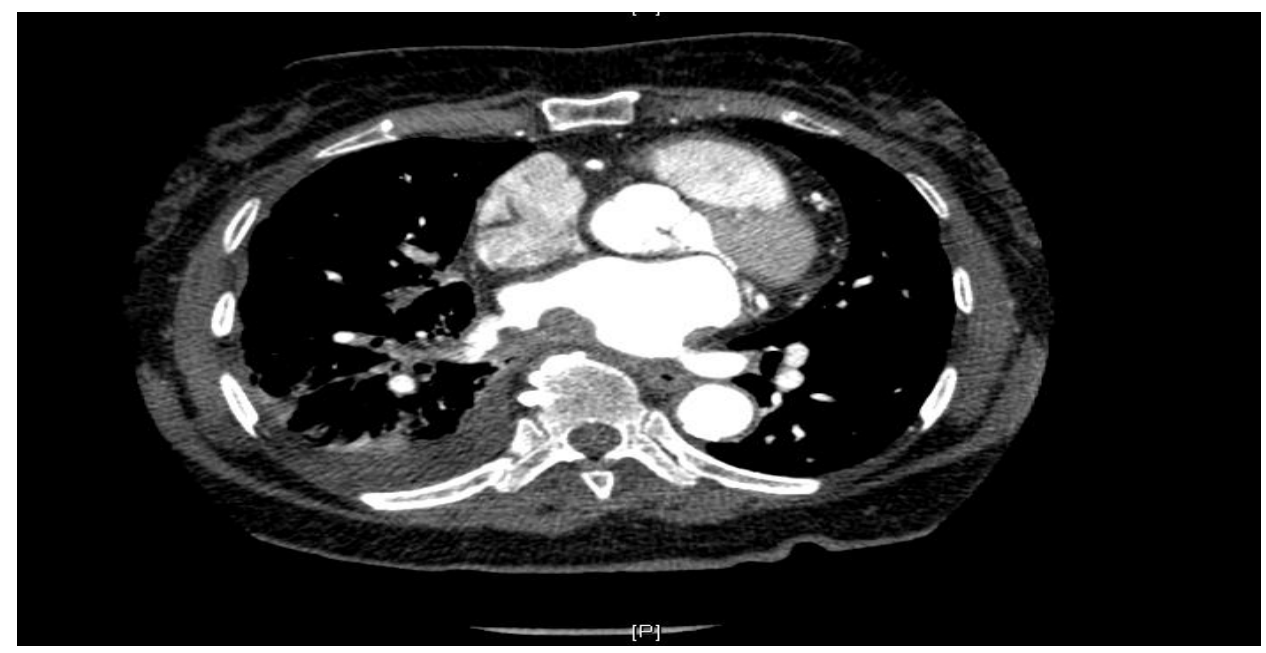

Figure 1. Computed tomography of the chest demonstrating a bi-lobed atrial mass on the posterior wall of the left atrium measuring $3.3 \mathrm{~cm}$ and extending into the right inferior pulmonary vein. 


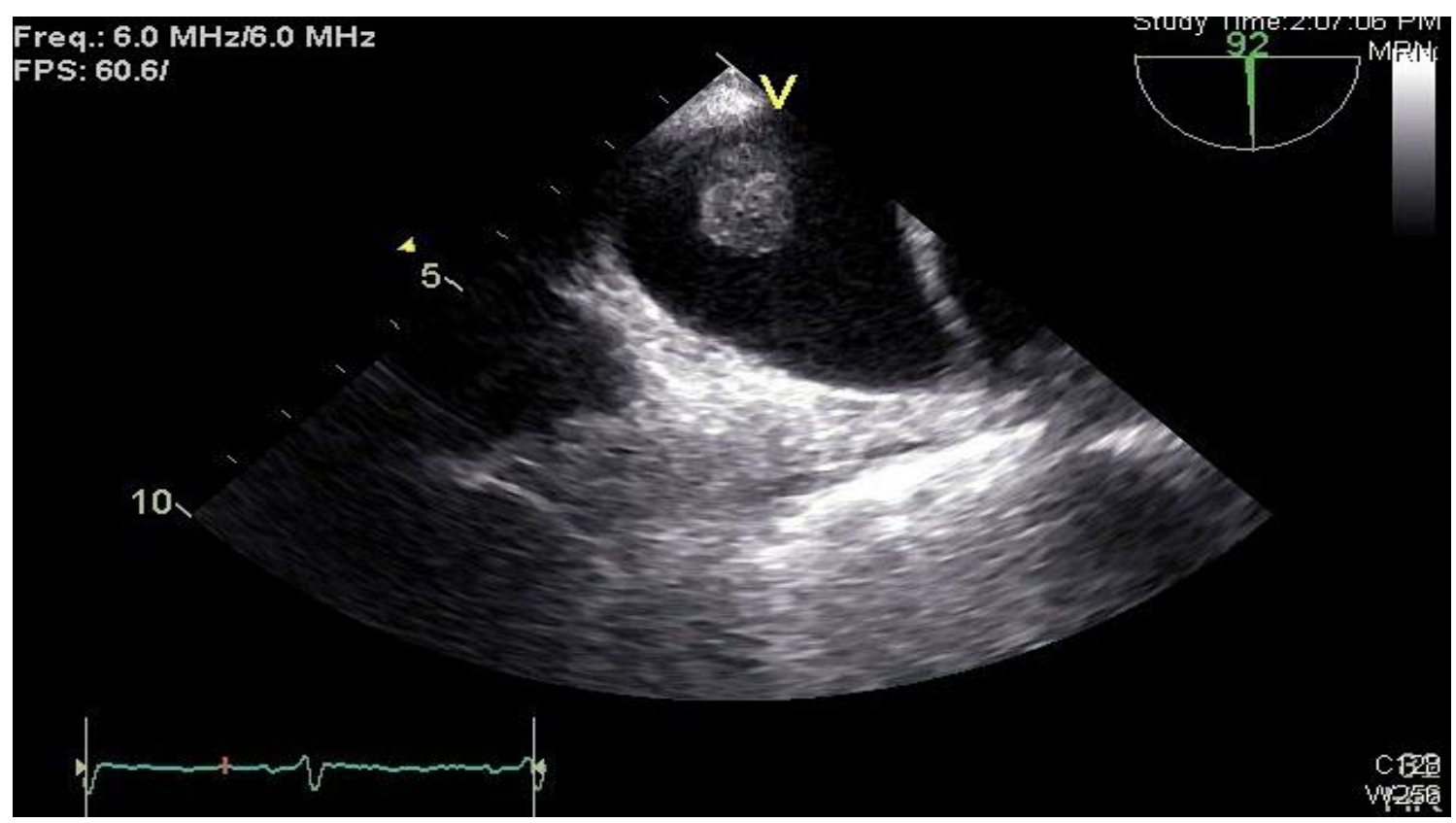

Figure 2. Transesophageal echocardiogram demonstrating a large $2.7 \times 1.8 \times 0.8 \mathrm{~cm}$ mobile echogenic mass attached to the left posterior atrial wall.

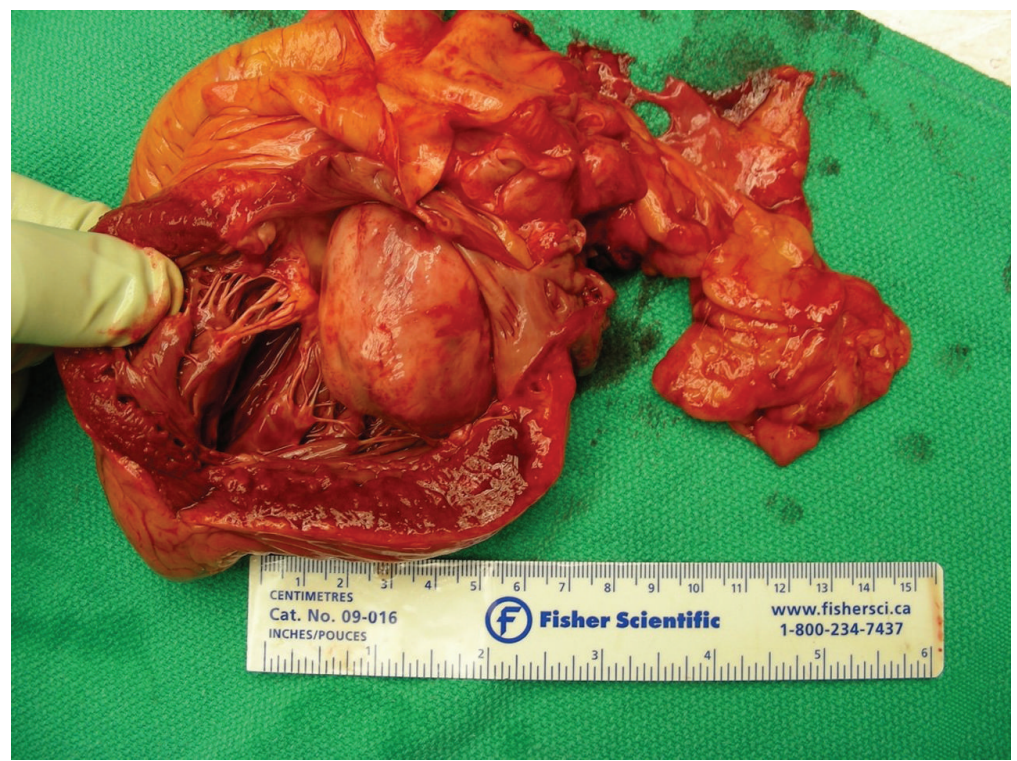

Figure 3. A mass is seen in the left atrium, attached to the posterior wall, measuring $5.0 \times 4.0 \times 2.5 \mathrm{~cm}$.

benign and classically originate from the pleura, but rarely can arise from extra-thoracic sites. ${ }^{8-10}$ Few reports have been published on malignant SFTs arising from the myocardium or pericardium, particularly those arising from the left heart. ${ }^{10-13}$ Metastatic disease from malignant SFTs have been reported originating from lung, skin, liver, bone, and adrenal gland, typically presenting late in the course of the disease. ${ }^{13}$ To our knowledge, this is the first reported case of embolic lesions involving the central nervous system arising from an intracardiac malignant SFT.

\section{Conclusion}

Our patient's clinical presentation is consistent with tumour emboli causing multifocal ischemic stroke and lung emboli from an intracardiac malignant solitary fibrous tumour. 
This case highlights the importance of considering a wide differential diagnosis for embolic lesions to the central nervous system when a patient presents with neurologic deficits involving multiple vascular territories. Although cardiac metastases may occur in patients with various primary malignancies, the presentation of multifocal ischemic strokes and seizures secondary to tumour emboli from a primary intracardiac malignant solitary fibrous tumour has not been reported to date.

\section{References}

1. Palacio S, Hart RG. Neurologic manifestations of cardiogenic embolism: an update. Neurolog Clin 2002;20(1):179-93.

2. Roberts WC. Primary and secondary neoplasms of the heart. Am J Cardiol 1997;80(5):671-82.

3. Bussani R, De-Giorgio F, Abbate A, Silvestri F. Cardiac metastases. J Clin Pathol 2007;60(1):27-34.

4. Dias RR, Fernandes F, Ramires FJ, Mady C, Albuquerque CP, Jatene FB. Mortality and embolic potential of cardiac tumours. Arquivos brasileiros de cardiologia. 2014;103(1):13-18.

5. Park CK, Cho YA, Kim M, Shim HS. Malignant lymphoma arising in cardiac myxoma, presenting with peripheral arterial emboli. Cardiovasc Pathology 2018;32:26-29.
6. Mitomi M, Kimura K, Iguchi Y, et al. A case of stroke due to tumour emboli associated with metastatic cardiac liposarcoma. Intern Med (Tokyo, Japan). 2011;50(14):1489-91.

7. Garg N, Moorthy N, Agrawal SK, Pandey S, Kumari N. Delayed cardiac metastasis from phyllodes breast tumour presenting as cardiogenic shock. Texas Heart Inst J 2011;38(4):441-44.

8. Bishop JA, Rekhtman N, Chun J, Wakely PE, Jr., Ali SZ. Malignant solitary fibrous tumour: cytopathologic findings and differential diagnosis. Cancer Cytopathol 2010;118(2):83-89.

9. Gold JS, Antonescu CR, Hajdu C, et al. Clinicopathologic correlates of solitary fibrous tumours. Cancer 2002;94(4):1057-68.

10. Taguchi S. Primary cardiac solitary fibrous tumours. Ann Thoracic Cardiovasc Surgery 2015;21(4):329-31.

11. Flemming P, Maschek H, Werner M, Kreft A, Graeter T, Georgii A. [Solitary fibrous tumor of the epicardium]. Der Pathologe 1996;17(2):139-44.

12. Taguchi S, Mori A, Yamabe K, et al. Malignant solitary fibrous tumor of the left ventricular epicardium. Ann Thoracic Surg 2013;95(4):1447-50.

13. Cuadrado M, Garcia-Camarero T, Exposito V, Val-Bernal JF, Gomez-Roman JJ, Garijo MF. Cardiac intracavitary metastasis of a malignant solitary fibrous tumor: case report and review of the literature on sarcomas with left intracavitary extension. Cardiovasc Pathology 2007;16(4):241-47. 